\title{
Jornalismo
}

\section{Jogos cubanos: a ilha, hoje, em reportagens na primeira pessoa}

\author{
Cuban games: the island, nowadays, on first-person news reports
}

MÁrCio Serelle

Professor do Programa de Pós-Graduação em Comunicação Social, "Interações Midiáticas" da PUCMinas/MG/BR. <marcio.serelle@pq.cnpq.br>

\section{RESUMO}

Reportagens em primeira pessoa sobre o declínio da Revolução Cubana perfizeram, nos últimos anos, o movimento de troca da narrativa do grande périplo pelo pequeno relato ancorado em verdades pessoais. Este artigo examina duas dessas narrativas: a do norte-americano Patrick Symmes (2011), Cubano por trinta dias, e a do brasileiro Airton Ortiz (2010), Havana. Esses relatos têm sua força persuasiva na experiência intensamente subjetiva, em que o repórter submete o próprio corpo para testemunhar com autoridade a vivência dos cubanos. A partir da análise desses textos e com base em algumas considerações teóricas de Carlo Ginzburg (1989), no artigo "Ekphrasis e citação", acerca da potencialidade literária na historiografia, problematizam-se o efeito de verdade no testemunho jornalístico, sua relação com a autopsia e a vivacidade, como efeito estilístico. Busca-se, ainda, refletir acerca dessa modalidade de jornalismo, considerando-se as especificidades de seu testemunho - quando comparado àquele das catástrofes - e seus tensionamentos éticos.

Palavras-chave: Cuba; Reportagem; Testemunho.

\section{ABSTRACT}

First-person reports about the decline of the Cuban Revolution executed, in recent years, the movement from the narrative of the great journey to the small account, grounded in personal truths. This article examines two of those narratives: one by North-American Patrick Symmes (2011), Cuban for thirty days, and the Brazilian one by Airton Ortiz (2010), Havana. These reports have their persuasive force in the intensely subjective experience, in which the reporter inflicts to his own body to testify with authority as would the Cubans. From the analysis of these texts and based on some Carlo Ginzburg's (1989) theoretical considerations, in the article "Ekphrasis and quotation", about the literary potential on historiography, this paper discusses the effect of truth in the journalistic testimony, its relationship with autopsia and evidence, as a stylistic effect. This work also aims at reflecting on this type of journalism, considering the specificities of his testimony - when compared to that of disasters - and its ethical tensions.

Keywords: Cuba; Reports; Testimony. 
Tarrar em primeira pessoa o declínio da revolução cubana tornou-se, nas últimas 1 décadas, um modo exemplar de ponto de vista, comum a olhares estrangeiros e autóctones1, como se a falência do metarrelato fosse melhor narrada justamente pelo que o substituiu, o pequeno relato, realizando, nesse movimento, uma das teses centrais acerca da pós-modernidade. Lembremos que, para Lyotard (2008), a condição pós-moderna define-se, fundamentalmente, pelo desuso dos dispositivos totalizantes e explicadores (a religião, a ciência, o marxismo etc.). Nela, "a função narrativa perde seus atores, os grandes heróis, os grandes perigos, os grandes périplos e o grande objetivo" (Lyotard, 2008, p. 16), restando, apenas, no desencanto, relatos circunscritos às verdades pessoais.

Essa decomposição marca a passagem das coletividades sociais para a singularidade do indivíduo, que é narrada, em oposição à épica, de forma autocentrada. Os relatos em primeira pessoa perfazem, de modo geral, uma guinada contemporânea, a que Sarlo (2007) denomina "subjetiva", de "devolução da palavra ao sujeito", que persuade pelo imediatismo da experiência: "falo porque sofri na própria carne o que conto" (Sarlo, 2007, p.117). Nos últimos anos, a primeira pessoa multiplicou-se tanto em narrativas sobre o passado como em relatos de circunstância, sejam eles, por exemplo, reportagens jornalísticas ou textos das mídias sociais, em que a vivência já vem à tona narrada - daí a menção ao caráter epidérmico da subjetividade na atualidade, à diferença daquela cultivada na interioridade, como a plasmada pelo romance burguês.

Os dois relatos em primeira pessoa de estrangeiros acerca de Cuba que serão analisados neste artigo, os do repórter norte-americano Patrick Symmes (2011) e do jornalista e escritor brasileiro Airton Ortiz (2010), afinam-se, em princípio, por narrar o desmanche de uma utopia, por sua força de persuasão ancorada na subjetividade e pela aproximação com movimentos do jogo e do entretenimento. Interessa-nos, portanto, como base em algumas considerações teóricas de Carlo Ginzburg (1989), no artigo 
Ekphrasis e citação, sobre a historiografia, formular algumas questões acerca da narrativa subjetiva no jornalismo: por que se apreendem como verdadeiros fatos narrados em primeira pessoa? Como se dá esse deslocamento e sob qual circunstância - tratando-se, aqui, especificamente de relatos jornalísticos -, da evidência, fundada na prova externa e objetiva, para a evidência (euidentia), de caráter retórico, fundada na vivacidade do relato em primeira pessoa. Este estudo obedece, então, a dois movimentos, não excludentes, para investigar essas reportagens acerca de Cuba hoje: um de ordem narrativa, que joga luz sobre questões de linguagem e procura compreender, nesse domínio, o efeito de verdade do testemunho; outro de ordem ética, que, atento às especificidades da realidade cubana, recupera teórica e historicamente os preceitos da guinada subjetiva que atuam na conformação do campo biográfico contemporâneo para tentar apontar especificidades dessa modalidade de testemunho jornalístico.

Nas duas reportagens, o jogo de se viver em Havana, como vivem os cubanos ou, como um estrangeiro que recusa os limites do aparato turístico oficial dá-se por meio da experiência a que o sujeito submete o próprio corpo para narrar com autoridade. A ideia de jogo parece-nos aqui apropriada pelo ingresso voluntário desses jornalistas no mundo cubano, como se esse, regido por regras próprias, estivesse entre parêntesis, com espaço e tempo restritos - a ilha e o período de duração da viagem - numa realidade paralela e episódica, ao modo dos reality shows. Como nos diz Luhmann (2005, p. 94), "o jogo é um tipo de duplicação da realidade, no qual a realidade tomada como jogo é separada da realidade normal, sem que esta última precise ser negada". No caso desses relatos, a duplicação de mundos toca limites éticos, uma vez que, para os cubanos, evidentemente, a situação narrada não é episódica.

A narrativa jornalística em primeira pessoa não é, como discutimos alhures (Serelle, 2009), uma pertinência da contemporaneidade. Presente, por exemplo, na ascensão da reportagem brasileira, no início do século $X X$, esse tipo de relato, conquanto 
tensione os valores de objetividade do campo, é bastante recorrente em narrativas de viagem, em que o jornalista coloca em relevo, por meio de sua subjetividade, o exótico com que entra em contato. Nesse processo, ocorrem tentativas de tradução e de cotejo entre culturas, que acabam por reverberar na formação do próprio sujeito que narra, como no "culto romântico da Viagem - da busca do eu no confronto com o outro" (Seligmann-Silva, 2005, p. 191). No entanto, destaca-se, hoje, a frequência cada vez maior com que a reportagem adota o ponto de vista em primeira pessoa, de que irrompe, por vezes, um testemunho vinculado, como dissemos, à noção de uma performance em jogo. Podemos citar como exemplo dessa repetição continuada uma série de reportagens da revista Época, publicadas em 2009, como "Encarei meu DNA", em que a repórter Cristiane Segatto se submete, a pedido do editor, ao mapeamento de seu código genético; "Como virei um peixe de aquário", de Gisela Anuate, que experimenta o Acquabox, cilindro de vidro com água em que a pessoa fica submersa para relaxamento, ao mesmo tempo em que, se torna peça decorativa em sala de visita; "Minha vida amorosa na internet", em que um repórter anônimo narra suas experiências no site de relacionamento Par perfeito².

\section{Um repórter da fome, outro do desregramento}

A reportagem de Symmes, jornalista especializado em América Latina, foi publicada originalmente em outubro de 2010 na Harper's Magazine, com o título "30 days as a cuban - pinching pesos and dropping pounds" [30 dias como um cubano - catando pesos e perdendo quilos 3 ] e republicada na Folha de S. Paulo, no caderno "Ilustríssima", em 30 de janeiro de 2011 (Cubano por 30 dias). O “desafio" do repórter é passar um mês em Havana com apenas 15 dólares - o equivalente ao salário de um jornalista cubano, de um "intelectual oficial" (Symmes, 2011, s.p.), que recebe em peso não conversível4. O racionamento, a saída pela esquerda (ou pelo "mercado negro", que inclui pequenos 
golpes e desvios, utilizados cotidianamente pelos cubanos para burlar as restrições impostas pelo governo e pela carestia), o desemprego, a precariedade do transporte público e a vigilância são abordados na medida em que o relato se constrói como o de um artista da fome, permeado pelo sarcasmo - refletido, por exemplo, no título da segunda parte do artigo, na tradução brasileira: “O regime cubano”. Cáustico, Symmes registra, assim, o início de sua experiência com a fome: "Eu não tinha almoçado. Tentei ler, mas só havia trazido livros sobre dificuldades e sofrimentos, como Os miseráveis" (Symmes, 2011, s.p.). De Victor Hugo, lido posteriormente, o jornalista retira uma descrição da fome só de fato facultada àquele que resiste na arte de viver sem nada, ainda bem diferente de viver com pouco: “Quando a pessoa não comeu a sensação é muito estranha... Ela rumina aquela coisa inexprimível, a amargura. Uma coisa horrível, que envolve dias sem pão e noites sem sono" (Hugo apud Symmes, 2011, s.p.)

A fome torna-se, portanto, o eixo central da experiência do repórter, que apreende Havana como uma espécie de pátio de desmanche, em que, conquanto a visível decrepitude, não há resistência possível devido à letargia dos famintos, que "se dispõem a aplaudir o regime em troca de um sanduíche" (Symmes, 2011, s.p). Atento ao anacronismo e à decadência da revolução, Symmes coloca também em relevo o retorno da prostituição, atividade que o governo de Fidel orgulhava-se de ter banido5. Sobre isso, a cena escolhida por Symmes para a reportagem condensa diversos problemas (a fome novamente, a gravidez na adolescência e a prostituição) que apontariam o fracasso daquela sociedade. "Até que ponto", ele se pergunta, "uma pessoa precisa estar faminta para se tornar parecida com a adolescente pela qual passei em uma calçada de Vedado naquela tarde; ela trazia um bebê no colo, mas se voltou para mim e disse: "Deseas una chica sucky sucky?" (Symmes, 2011, s.p).

O repórter narra, como num diário, sua convivência com a fome, cujos primeiros sintomas são dor na gengiva, salivação e ansiedade. Já na etapa final da viagem, 
Symmes, alguns quilos mais magro, descreve, assim, seu experimento: "Minha primeira semana havia sido dolorosa e acompanhada por uma fome mortal. A segunda dolorosa e apenas moderadamente faminta. Agora, na terceira, ainda que estivesse comendo menos que nunca, me sentia tranquilo, tanto física quanto mentalmente" (Symmes, 2011, s.p).

Uma das constatações possíveis é a de que a reportagem de Symmes - que, como estratégia de divulgação, foi antecipada por um podcast e um vídeo filmado pelo próprio jornalista e veiculado no You Tube - é um Supersize me às avessas. Neste documentário exibido em 2004, Morgan Spurlock sujeita-se a uma dieta também de 30 dias em que todas as refeições devem ser feitas no McDonald's. O documentarista registra, em conversas com a própria câmera e principalmente com médicos, os efeitos da fast food em seu corpo, que incluem sobrepeso, baixo desempenho sexual, danos no fígado, entre outros. Ideologicamente opostas, a reportagem de Symmes é orientada para narrar a falência do ideário comunista, do modo como aplicado em Cuba; a narrativa de Spurlock pertence a um conjunto de documentários da esquerda dos Estados Unidos, de que Michael Moore é o expoente, que pretende atacar os valores capitalistas, ancorados no liberalismo da sociedade norte-americana. (Lembremos, por exemplo, que, em um de seus documentários, Sicko (2007), sobre o deterioramento do sistema de saúde nos Estados Unidos, Moore exibe como um dos contrapontos o que ele considera como sucesso do sistema cubano). Em comum, no entanto, entre "30 days as a cuban" e Supersize me é, como dissemos, o caráter de submissão do corpo do repórter e do documentarista para retirar, da experiência voluntária, seu testemunho e o efeito de verdade.

A crônica-reportagem Havana, de Ortiz, adota, também, o princípio da imersão, na busca por aprender "a viver como os cubanos" (Ortiz, 2010, p. 60), e ressalta aspectos semelhantes no que se refere à crise na ilha, notadamente aqueles relacionados 
ao racionamento de alimentos e à prostituição. Embora sem a radicalidade do experimento do norte-americano, a narrativa de Ortiz esforça-se para se aproximar daquilo que julga ser a realidade cubana, que estaria encoberta pelo aparato propagandístico do regime ou pela condição de isolamento do País. Por isso, ele consegue pesos cubanos, aprende a usar o sistema de transporte coletivo, come as mesmas refeições que os havaneses, divide apartamento com locais e faz escambo, para conseguir dinheiro. No entanto, ainda que faça oposição à teoria da ditadura benigna, o narrador é sensível aos valores revolucionários, como na epígrafe, que cita Che Guevara 6 .

Havana, com seus capítulos titulados, em sua maioria, com nomes de espaços de valor cultural e histórico (Casa de Las Américas, El Floridita, Malecón, Edifício Bacardí, Centro Habana), ambiciona ser um guia turístico à margem dos grandes hotéis de Varadero. A cidade na primeira pessoa de Ortiz é celebrada pelo sexo, bebida e música, em relato que oscila entre o gonzo e a ficção marcadamente biográfica de Pedro Juan Gutiérrez, que parece ter inaugurado, com Trilogia suja de Havana, esse tipo de narrativa sobre o declínio, que não deixa, contudo, de fazer pulsar o sensualismo da ilha. A prosa de Gutiérrez é citada no capítulo 51 da reportagem, em que Ortiz procura na livraria La Internacional por uma obra do autor. A vendedora informa-lhe que se podem encontrar livros de Gutierrez em Havana, mas não em livrarias, pois o autor é acusado de ter "escrito algumas coisas fortes" (Ortiz, 2010, p. 225). Para Ortiz, "Pedro Juan escrevera sobre a miséria humana, um mergulho para descobrir até onde as pessoas vão na luta para cumprir a lei número um da natureza: sobreviver" (Ortiz, 2010, p. 225).

Como veremos, esse "mergulho" na realidade cubana, com determinada visada do escombro e da cultura, será também ensaiado pelo repórter. Na cadência de Gutiérrez, Ortiz descreve, assim, uma sessão musical no Callejón de Hamel, centro 
cultural pouco frequentado por turistas, mas que reúne músicos e bailarinos cubanos:

As bandas e os cantores se alternavam, e todos dançavam. E bebiam. E fumava. Um dos músicos usava uma camiseta da Seleção Brasileira de Futebol. O cara tocava atabaque com rara habilidade, parecia ter nascido em Salvador. Chocalhos, agogôs, batás (tumbadores) e congas eram repercutidos em profusão. Homens e mulheres vestidos de branco, da cabeça aos pés, cheios de colares, davam shows. Exibiam os dotes físicos uns para os outros, um duelo de sensualidade.

(Ortiz, 2010, p. 67)

De observador a participante, Ortiz é, então, tirado para dançar por Mercedita, uma "negra muito fina", feita de "músculos e fibras, quase nada de gordura" (Ortiz, 2010, p. 68).

Em outro episódio, referente a uma incursão em Havana velha, parte antiga da cidade não restaurada, o repórter reafirma seu método de integração à realidade investigada, quando é abordado na rua por uma jovem prostituta e levado para dentro de uma da casa, em que uma família (um casal e um bebê) assiste à tevê. Iniciada a negociação por sexo, Ortiz diz que está disposto a pagar, mas pela irmã da jovem, que é casada. Para sua surpresa, o próprio marido autoriza, e se retira da sala. Buscando formas de escapar ao acordo, que é de fato cancelado, ele escreve um breve monólogo em que expõe o trespasse de limites éticos: 
Como dizer: olha, desculpe, mas não desejo sexo. Queria tão somente conhecer a casa e, já que a situação evoluiu nesse sentido, ver até que ponto um ser humano desce na luta pela sobrevivência imediata. Onde está o fundo do poço? Só queria saber do que a alma humana é capaz. Até onde vai a sordidez. Tanto a de vocês quanto a minha.

Como dizer essas coisas? Como dizer que sou um repórter em busca de informações e que para isso coloco as pessoas em situações de tamanha humilhação? Como dizer que as pautas justificam os meios?

Impossível dizer.

(Ortiz, 2010, p. 222)

Em face desses dois relatos jornalísticos de estrangeiros, é bastante curioso que, no post "Venha e vivencie", publicado em 19 de janeiro de 2009, no blog Geração Y, a cubana Yoani Sánchez, saturada pelos anúncios turísticos do governo, sugere, ironicamente, como atrativo, justamente um programa de estadia à cubana, em que os agentes sugeririam, ao invés dos hotéis de luxo em Varadero ou Cayo Coco, "casas de cômodos em Buena Vista e um albergue abarrotado de refugiados dos furacões" (Sánchez, 2009, p. 139). Os turistas não poderiam, ainda, usar pesos conversíveis e deveriam passar seus 15 dias com o salário médio cubano de um mês: trezentos pesos cubanos. No final da viagem, segundo ela, os excursionistas "iriam embora mais magros, mais tristes, com uma obsessão pela comida que será saciada nos supermercados dos seus países [...]" (Sánchez, 2009, p. 140). Por esses recentes relatos jornalísticos, percebe-se que a modesta proposta de Sánchez, embora absurda, na chave de Swift, já foi acatada. Os expedicionários (o livro de Ortiz pertence a uma 
coleção chamada "Expedições Urbanas") voltam de fato mais magros, porém não mais tristes, haja vista a naturalidade com que a denúncia se entrelaça ao entretenimento nesse jornalismo fora da ilha.

\section{Autopsia e efeito de verdade}

Esses relatos jornalísticos em primeira pessoa recuperam aspectos de uma longa tradição, com raízes na historiografia antiga, que se funda no caráter imediato do testemunho e na potencialidade literária para provocar seus efeitos de verdade. Roberto Saviano (2009, p. 6), que narra Gomorra também a partir de sua vivência, cita como preceito uma máxima de Xenofonte: "Não confie em quem escreve sobre coisas não vividas". A frase reabilita uma concepção grega e romana de historiografia cujo método consistia, preferencialmente, da observação direta - o objeto dessas narrativas era, portanto, a história coeva ou do passado recente. Como explica Ginzburg (1989, p. 225), “o historiador era, antes de mais nada, uma testemunha, tão perto quanto possível dos acontecimentos de que falava; a ênfase sobre a autopsia, sobre a visão directa, significava que fatos baseados em ouvir-dizer eram considerados de natureza inferior". Ginzburg (1989, p. 219) retira, de Políbio, fragmento que confirma, naquele contexto, a valorização do campo da experiência direta: "Avaliar as coisas a partir do que se ouviu dizer não é o mesmo que avaliá-las a partir do que efetivamente se presenciou. Há nisto uma grande diferença. Em todos os assuntos, uma certeza fundamentada no testemunho dos olhos [...] é duma enorme importância".

Na base dessa noção historiográfica está, portanto, o testemunho, que, etimologicamente, como recupera Agamben (2008), é representado em latim por dois termos: testis e superstes. O primeiro significa "aquele que se põe em terceiro em um processo ou em um litígio entre dois contendores" (Agamben, 2008, p. 27), 
sendo chamado, na cena jurídica, para narrar sua versão. O segundo “indica aquele que viveu algo, atravessou até o final um evento e pode, portanto, dar testemunho disso" (Agamben, 2008, p. 27). Esse "ver com os próprios olhos" da testemunha, a autopsia, parece-nos, contudo, tanto um ponto de partida como de chegada dessa historiografia e dessa reportagem em primeira pessoa, pois aquilo que foi presenciado deve ser narrado com vivacidade, para que a cena ressoe no leitor, como se ele estivesse também diante do evento. Ginzburg recupera, em Homero, o termo grego enargeia (vivacidade), para denominar esse efeito estilístico, de clareza e nitidez, que emerge de uma narração precisa, "que não descuida nenhum pormenor e que não suprime nada" (Demétrio apud Ginzburg 1989, p. 221). Esse detalhismo, de que depende o efeito de real (Barthes, 2004), caracteriza também o testemunho contemporâneo. Nele, como analisa Sarlo (2007, p. 52), "a proliferação do detalhe individual fecha ilusoriamente as fendas da intriga como se ela pudesse ou devesse representar um todo, algo completo e consistente porque o detalhe o certifica, sem ter de mostrar a sua necessidade." A verdade íntima do relato, de acordo com Sarlo, apóia-se justamente no detalhe, pois o narrador que consegue dar conta do pormenor insignificante - como o barômetro na sala burguesa da descrição de Flaubert, referido por Barthes (2004) em seu ensaio "O efeito de real" - não deixaria de fora o imprescindível.

O termo enargeia foi traduzido para o latim como euidentia, de onde deriva a palavra portuguesa "evidência", que, em uma de suas acepções, ligada à retórica, ainda guarda o sentido de descrição viva e minuciosa de um objeto, por meio da enumeração de suas particularidades. No entanto, o sentido de evidência como prova material parece ser, hoje, o mais corrente, principalmente na língua inglesa, em que evidence designa informação usada em julgamentos, obtida, muitas vezes, a partir de documentos e objetos. Em português, encontra-se ainda a palavra "enargia", mais próxima ao grego, no sentido de representação ou descrição extremamente realística. 
A enargeia era, portanto, na historiografia antiga o que a ekphrasis - série de descrições de objetos artísticos, reais ou fictícios - objetivava. A enargeia era alcançada quando um relato proporcionava, por meio da descrição, a vivacidade do narrado, realizando uma demonstratio, que aponta um objeto invisível. Com seu núcleo retórico apagado pela noção aplicada à matemática, a palavra latina demonstratio - em português "demonstração" -, como explica Ginzburg,

[...] implicava o gesto do orador apontando para um certo objecto inexistente, tornado visível - enarges - ao seu auditório através do poder quase mágico das suas palavras. De modo semelhante, o historiador estava apto a transmitir a sua própria experiência - directa, como testemunha, ou indirecta - pondo uma realidade invisível debaixo dos olhos dos seus leitores. Enargeia era um meio de realizar autopsia, ou seja, visão directa, pela acção do estilo.

(Ginzburg, 1989, p. 220).

A verdade da historiografia era, portanto, uma forma de persuasão pelo efeito da vivacidade do relato, que deveria apenas marginalmente ser submetido "ao teste objetivo da realidade" (Ginzburg, 1989, p. 223). Pode-se dizer que esses relatos jornalísticos de estrangeiros em primeira pessoa sobre Cuba atingem a vivacidade pela assunção de que a realidade ali narrada foi tanto vista como sentida no próprio corpo da voz que enuncia e, que, por isso, consegue descrever com detalhes experiências como o crepúsculo havanês visto do Malecón (Ortiz, 2010), ou a própria fome (Symmes, 
2011). A persuasão dá-se, portanto, pela marcação do lugar do enunciador, próximo ao evento, vinculada ao detalhismo, como procedimento discursivo, que faz emergir determinado efeito de verdade.

Convém, no entanto, ressaltar alguns aspectos da condição testemunhal dessas reportagens que podem elucidar alguns estratagemas narrativos e as implicações éticas desse jornalismo contemporâneo, ancorado na primeira pessoa. Nos casos aqui estudados, a intenção de testemunhar antecede a própria experiência, que é, então, vivenciada já de maneira planejada e sob determinadas regras, a que o sujeito se submete não por contingência, mas para participar de uma realidade à parte, condição a que nos referimos, neste artigo, como jogo. “Oi, eu sou Patrick Symmes, estou em Havana, Cuba, vivendo 30 dias como um cubano [...]. Esse será um pequeno experimento a que infligirei meu próprio corpo para ver como é para os cubanos tentar atravessar um mês inteiro nesse sistema", narra o repórter em seu podcast ${ }^{7}$. Ou seja, à diferença daquelas testemunhas envolvidas, de modo indesejado, ou não, em situaçõeslimite que se tornam mais potentes que elas, subjugando-as e confiscando sua própria subjetividade (como no caso da Shoah ou das ditaduras na América Latina), esses repórteres agem, de modo voluntário, em busca do testemunho, que aparentemente torna-se mais verdadeiro pela condição do jogo à cubana.

Nas situações-limite, o testemunho é traumático e lacunar, pois precisa lidar, muitas vezes, com um horror indizível, que se recusa à metáfora e que afasta audiências. $\mathrm{Na}$ análise que Rancière (2010, p. 137) faz de uma sequência do filme Shoah, de Claude Lanzmann, em que um barbeiro, que tosquiava aqueles prestes a entrar na câmara de gás, não suporta continuar seu relato, mas é estimulado pelo diretor, a palavra da testemunha torna-se virtuosa por três razões negativas: "primeiro porque é o oposto da imagem, que é idolatria; porque é a palavra do homem incapaz de falar; porque é a palavra de um homem obrigado à palavra por uma palavra mais poderosa que a sua". 
As reportagens-testemunho analisadas neste artigo tampouco podem ser igualadas, do ponto de vista de suas reivindicações, às narrativas em primeira pessoa dos próprios cubanos - os relatos autóctones a que nos referimos na abertura deste texto -, que as utilizam como tática para recuperação de um território subjetivo, confiscado pelo regime. Para uma geração que, conforme a narradora Nieve Guerra, alterego da escritora Wendy Guerra no romance Todos se vão, é identificada por não conhecer “o eu, só o nós" (Guerra, 2011, p. 123), a escrita íntima torna-se uma forma de cura. "Meu diário é [...] meu remédio, o que me mantém de pé" (Guerra, 2011, p. 130), diz a personagem, que busca romper pela escrita o estado de coisificação a que foi submetida. De modo semelhante, a blogueira Yoani Sánchez $(2009$, p. 17) afirma que a perda da privacidade - já, segundo a autora, tão sacrificada no projeto coletivo do "Homem Novo" comunista, que teria lhe invadido mesmo a reserva do corpo - é, na exposição da vida pela internet, uma forma de resistência, o que "evita que seja devorada pela engrenagem".

Diferentemente, conquanto sua vivacidade e força de denúncia - está mais presente na narrativa de Symmes que na de Ortiz -, as reportagens dos estrangeiros, pela submissão às regras de um jogo e pela linguagem irônica e jocosa com que se testemunha o exótico cubano, parecem, ao fim e ao cabo, sublinhar o caráter autônomo do mundo ali narrado, num ponto em que o jogo encontra-se com o entretenimento, em sua interação com os leitores ou espectadores. Nessa lógica, há sempre a possibilidade de se experimentar essas narrativas do modo como assistimos, por exemplo, a um filme fortemente realista, mas que nos deixa um espanto débil, facilmente esquecível, haja vista que o entretenimento, embora nos envolva, diz-nos, a todo tempo, que a responsabilidade do que ocorre naquele espaço, que pode ser isolado de nossa realidade, não é nossa. E essa ambiguidade caracteriza esses relatos jornalísticos, que, por mais que ancorem seu efeito de verdade em uma retórica do vivido, a realidade 
aparece neles sob uma luz de cenário, em que o holofote acompanha seus protagonistas como a atores.

\section{REFERÊNCIAS}

AGAMBEN, Giorgio. O que resta de Auschwitz: o arquivo e a testemunha (Homo Sacer III). Trad. Selvino J. Assmann. São Paulo: Boitempo, 2008.

BARTHES, Roland. O rumor da língua. Trad. Mario Laranjeira. São Paulo: Martins Fontes, 2004.

GINZBURG, Carlo. Ekphrasis e citação. In: GINZBURG, Carlo. A micro-história e outros ensaios. Trad. António de Arino. Lisboa: Difel; Rio de Janeiro: Bertrand Brasil, 1989. p. 215-232.

GUERRA, Wendy. Nunca fui primeira dama. Trad. Josely Vianna Baptista. São Paulo: Saraiva, 2010.

GUERRA, Wendy. Trad. Josely Vianna Baptista. Trad. Josely Vianna Baptista.Todos se vão. São Paulo: Saraiva, 2011.

LUHMANN, Niklas. A realidade dos meios de comunicação. Trad. Ciro Marcondes Filho. São Paulo: Paulus, 2005. LYOTARD, Jean-François. A condição pós-moderna. Trad. Ricardo Corrêa Barbosa. Rio de Janeiro: José Olympio, 2008.

MORAIS, Fernando. A ilha: um repórter brasileiro no país de Fidel Castro. 30a․ Ed. São Paulo: Companhia das Letras, 2001.

ORTIZ, Airton. Havana. Rio de Janeiro: Rercord, 2010.

RANCIÈRE, Jacques. A imagem intolerável. RANCIÈRE, Jacques. O espectador emancipado. Trad. José Mirando Justo. Lisboa: Orfeu Negro, 2010. p. 123-153.

SÁNCHEZ, Yoani. De cuba, com carinho. Trad. Benivaldo Araújo e Carlos Donato Petrolini Jr. São Paulo: Contexto, 2009.

SARLO, Beatriz. Tempo passado - cultura da memória e guinada subjetiva. Trad. Rosa Freire D’Aguiar. São Paulo: Companhia das Letras; Belo Horizonte: Ed. UFMG, 2007.

SAVIANO, Roberto. O homem blindado. Entrevista. Folha de S. Paulo. São Paulo, 26 de abril de 2009. Mais! p. 5-6.

SELIGMANN-SILVA, Márcio. O local da diferença. - ensaios sobre memória, arte, literatura e tradução. São Paulo: Ed. 34, 2005. 
SERELLE, Márcio. Jornalismo e Guinada Subjetiva. Estudos em jornalismo e mídia. Florianópolis: Programa de Pós-Graduação em Estudos de Jornalismo da UFSC, ano VI, n. 2, p. 33-44, jul./dez. 2009.

SYMMES, Patrick. Cubano por um mês. Folha de S. Paulo. Ilustríssima. 30 de janeiro de 2011. Disponível em: <www1.folha.uol.com.br/ilustrissima/867590-cubano-por-30-dias.shtml>. Acessado em: 03 jul. 2011.

\section{NOTAS}

1 Neste artigo, trataremos principalmente de relatos de estrangeiros em primeira pessoa sobre Cuba. Sobre a recuperação do "eu" em narrativas dos próprios cubanos, ver, como exemplo, os posts de Yoani Sánchez em Geração Y (www.desdecuba.com/generaciony), e os romances autobiográficos de Wendy Guerra, Todos se vão e Nunca fui primeira dama.

2 As matérias foram publicadas, respectivamente, nas edições de 20 de abril, 28 de maio e 21 de setembro de 2009.

3 Tradução livre. O título em inglês faz também o trocadilho entre pesos, moeda cubana, e pounds, libras, usadas tanto como moeda (libras esterlinas) como na medida de peso corporal.

4 Em Cuba, atualmente, vigoram duas moedas: os pesos cubanos e os pesos conversíveis. Os primeiros, que valem bem menos na comparação com o dólar, são usados apenas pelos cubanos em sua economia doméstica; os convertibles, em paridade com o dólar, são acessíveis apenas a estrangeiros e a uma parcela da população da ilha. Com eles, é possível comprar produtos importados, hospedar-se em hotéis de luxo e comer em restaurantes destinados a turistas.

5 Ver a esse respeito o capítulo "O cotidiano", de A ilha, de Fernando Morais (2011). Nessa parte da reportagem, o jornalista, ainda não convencido de que a prostituição havia sido extinta no país, sai, segundo ele em vão, em busca de bordéis e de garotas de programa. O combate à atividade torna-se, após a revolução, um importante contraponto ao capitalismo exploratório que dominava Cuba, que chegou a ter, segundo dados oficiais, 100 mil prostitutas.

6 "Se você é capaz de tremer de indignação a cada vez que se comete uma injustiça no mundo, então somos companheiros" (Guevara apud Ortiz, 2010, s.p.)

7 Disponível em: <http://patricksymmes.com/Patrick_Symmes_Home_Page/Articles.html>. 